\title{
Life and death as a T lymphocyte: from immune protection to HIV pathogenesis
}

\author{
Nienke Vrisekoop ${ }^{\mathrm{a}}$, Judith N Mandl ${ }^{\mathrm{x}}$ and Ronald N Germain
}

\begin{abstract}
Address: Lymphocyte Biology Section, Laboratory of Immunology, National Institute of Allergy and Infectious Diseases, National Institutes of Health, 10 Center Dr MSC-1892, Bethesda, MD 20892, USA.

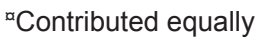

Correspondence: Nienke Vrisekoop. Email: vnienke@niaid.nih.gov
\end{abstract}

\begin{abstract}
Detailed analysis of $\mathrm{T}$ cell dynamics in humans is challenging and mouse models can be important tools for characterizing $\mathrm{T}$ cell dynamic processes. In a paper just published in Journal of Biology, Marques et al. suggest that a mouse model in which activated $\mathrm{CD}^{+}{ }^{+} \mathrm{T}$ cells are deleted has relevance for HIV infection.
\end{abstract}

See research article http://jbiol.com/content/8/10/93

T lymphocytes have a difficult existence. As mature cells, they are essential for immunity to infection, but in the early stages of their development in the thymus, more than $90 \%$ of them fail selection for the appropriate antigen receptors and die before export to the peripheral immune system. Those that achieve maturity spend weeks, months or even years circulating through the body, in constant search of a foreign antigen that their antigen-specific receptor can recognize, and needing continuously to compete for trophic signals necessary for their survival. Most fail to find an antigenic match and remain as small resting cells until death. A few encounter the right partner and undergo a transient bout of exponential clonal expansion, only for more than $90 \%$ of these progeny to be lost by apoptosis shortly after the antigen is cleared. The remaining $10 \%$ are maintained as memory cells (Figure 1), conferring lasting protection.

In normal individuals the $\mathrm{T}$ cell population shows excellent homeostatic control, with stable numbers for decades in adult humans, except for intermittent bursts of expansion during infection. Moreover, this homeostasis applies not only to the total number of $\mathrm{T}$ cells but to the proportions of these cells in the two major functional subsets of $\mathrm{T}$ lymphocytes $-\mathrm{CD}^{+} \mathrm{T}$ cells, whose principal function is to kill virus-infected cells, and $\mathrm{CD}_{4}{ }^{+} \mathrm{T}$ cells, which are critical for activating other immune cells, including $\mathrm{CD}^{+}$ $\mathrm{T}$ cells and the $\mathrm{B}$ cells that secrete antibodies. Understanding what happens to the performance of the immune system when this balance is disturbed is of both fundamental interest and clinical relevance. In perhaps one of the most relevant examples, HIV-infected individuals lose their $\mathrm{CD} 4^{+} \mathrm{T}$ cells, a loss that results in acquired immunodeficiency syndrome (AIDS) and death from secondary infections if the original infection is untreated.

In this issue of Journal of Biology, Marques et al. [1] present a novel genetic approach to eliminating $\mathrm{CD}_{4}^{+}$ $\mathrm{T}$ cells that the authors present as a mouse model of HIVinduced $\mathrm{CD}_{4}{ }^{+} \mathrm{T}$ cell death. Marques et al. [1] marked activated $\mathrm{CD}_{4}{ }^{+} \mathrm{T}$ cells for elimination in mice through manipulation of the genetic locus encoding a protein known as OX40 (TNFRSF4), which is expressed by almost all antigen-stimulated (and thus activated) $\mathrm{CD}_{4}{ }^{+} \mathrm{T}$ cells [2]. Their strategy was to construct a mouse in which the Tnfrsf 4 gene encoding OX40 drives expression of Cre recombinase. This enzyme, in turn, mediates the activation of a gene encoding diphtheria toxin A fragment (DTA), whose expression results in the death of the activated $\mathrm{CD} 4^{+}$ $\mathrm{T}$ cell within 48 hours of induction of OX 40 expression. In these mice (referred to from here on as OX40-DTA mice),

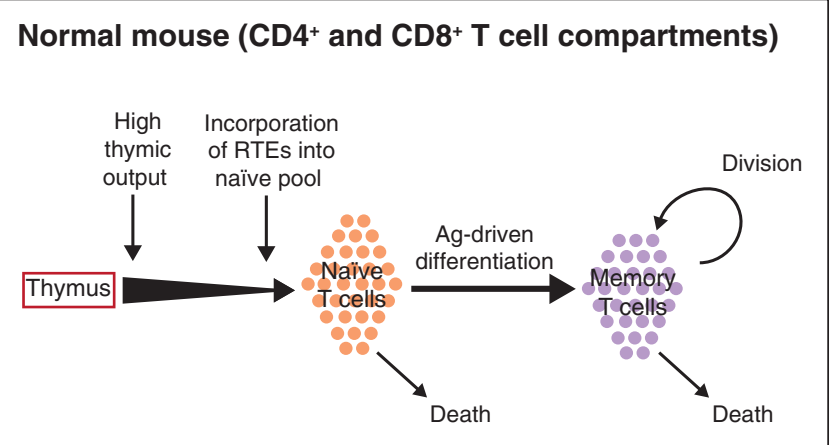

Figure 1

Schematic diagram of T cell dynamics in normal mice. Arrows denote the rate of death and division or of transit from one pool to another. Naïve T cells are T cells that have matured and left the thymus where they are generated, but have not yet encountered antigen. RTEs, recent thymic emigrants; Ag, antigen. 
about $55 \%$ of memory $\mathrm{CD} 4^{+} \mathrm{T}$ cells are always in the process of being deleted, whereas other immune cell populations, including naïve circulating $\mathrm{CD}_{4}^{+} \mathrm{T}$ cells, remain largely intact in overall number, although they show an increased rate of conversion to an activated state. The loss of activated $\mathrm{CD} 4^{+} \mathrm{T}$ cells is accompanied by partial immunodeficiency, which was seen following infection with Friend virus, influenza A virus and Pneumocystis murina. In these several respects, the model phenocopies some of the pathology of HIV infection, and it would be tempting, therefore, to conclude that these data show that direct cytopathicity of $\mathrm{HIV}$ for activated $\mathrm{CD} 4^{+} \mathrm{T}$ cells is the driving force in the $\mathrm{T}$ cell loss and resulting immunodeficiency in AIDS patients.

However, there is a complication. A subpopulation of $\mathrm{CD} 4^{+}$ $\mathrm{T}$ cells called $\mathrm{T}$ regulatory cells (Tregs) that suppresses immune activation and is thought to be important in preventing autoimmunity is specifically targeted in the OX40-DTA mouse. (The different subsets of $\mathrm{CD} 4^{+} \mathrm{T}$ cells are illustrated in Figure 2). Most Tregs constitutively express $\mathrm{OX}_{40}$ [3], and Marques et al. [1] find that more than $80 \%$ of these $\mathrm{T}$ cells are also lost in the OX40-DTA mice. Their data suggest that the loss of these regulatory and/or activated $\mathrm{CD}_{4}{ }^{+} \mathrm{T}$ cells results in substantial changes in $\mathrm{T}$ cell dynamics and induces chronic immune activation, which is a key characteristic of HIV infection. This raises interesting questions about both lymphocyte dynamics in the absence of antigen and the possible relevance of these results [1] to HIV infection.

\section{$\mathrm{CD}^{+} \mathrm{T}$ cell loss in HIV-infected individuals}

Although it is known that HIV kills activated $\mathrm{CD} 4^{+} \mathrm{T}$ cells, it is still a major unresolved question why these cells progressively decline after infection. It is clear that in infected individuals, the rate of loss of $\mathrm{CD}_{4}{ }^{+} \mathrm{T}$ cells is greater than the rate of production, so that the $\mathrm{CD} 4^{+} \mathrm{T}$ cell pool is gradually eroded over time, but how the balance between these processes is impaired remains to be determined. It is unlikely that direct killing of infected target cells by HIV is sufficient to cause $\mathrm{CD}^{+} \mathrm{T}$ cell depletion. Natural hosts for simian immunodeficiency virus (SIV), such as sooty mangabeys, do not progress to AIDS and maintain near-normal peripheral $\mathrm{CD}_{4}{ }^{+} \mathrm{T}$ cell numbers despite high rates of viral replication [4]. In fact, the level of immune activation during HIV infection is a better predictor of disease progression than is viral load. This chronic generalized immune activation is characterized by an increased rate of exit of $\mathrm{CD}_{4}^{+}$and $\mathrm{CD}^{+} \mathrm{T}$ cells and of natural killer (NK) cells from the resting state, increased $\mathrm{T}$ and $\mathrm{NK}$ cell turnover and death, polyclonal B cell activation with increased immunoglobulin levels, and elevated production of proinflammatory cytokines. Consistent with the reported association between chronic immune activation and disease progression, chronic immune activation is not

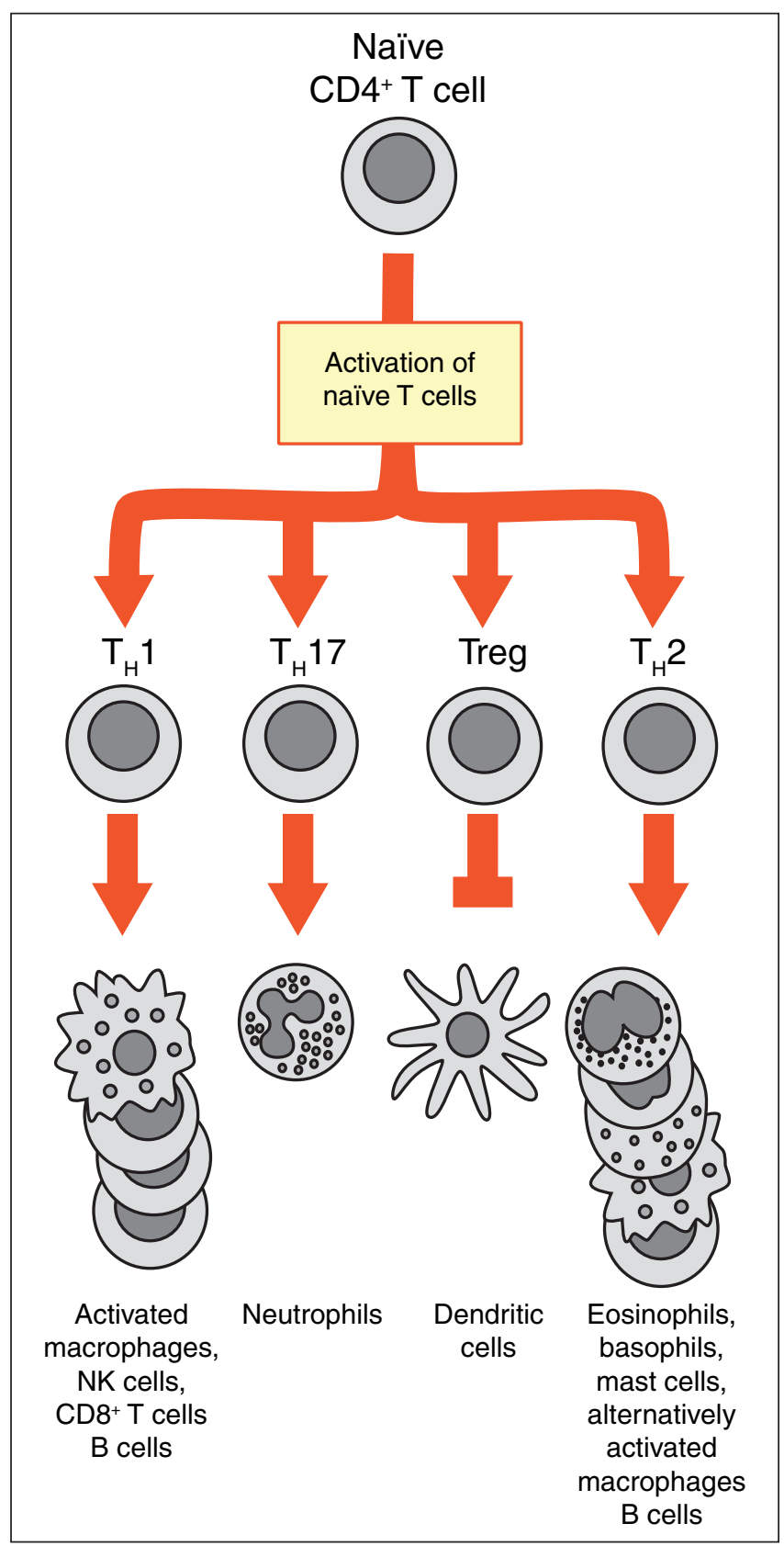

Figure 2

The major subsets of $\mathrm{CD}^{+} \mathrm{T}$ cells that differentiate from naïve circulating cells. Naïve T cells differentiate into at least four functional subsets following stimulation by antigen presented by dendritic cells, which are specialized for driving the activation of T cells and are thought to help direct their differentiation by differential secretion of cytokines determining the different subsets. Three subsets $-T_{H} 1, T_{H} 2$ and $T_{H} 17$ - activate other immune cells with distinct roles in immunity, including B cells, which secrete antibody, natural killer (NK) cells, which are important in defense against viruses, and inflammatory cells, such as neutrophils and macrophages (which also have non-inflammatory functions). The fourth subset shown here comprises regulatory $T$ cells (Tregs), which suppress the activation of the other subsets, partly by acting on dendritic cells. Modified from Figure 5-22 in DeFranco AL, Locksley RM, Robertson M: Immunity: The Immune Response in Infectious and Inflammatory Disease. London: New Science Press; 2007. 
seen following SIV infection in natural hosts that do not progress to AIDS [4].

Two general causal models have been proposed to account for the association between HIV infection and immune activation. The first is that $\mathrm{T}$ cell homeostasis is disrupted by the chronic activation of the innate immune system by HIV infection. The cells of the innate immune system recognize and are activated by conserved components of microorganisms, and include inflammatory cells and specialized cells known as dendritic cells that are critical in the activation of $\mathrm{T}$ lymphocytes (Figure 2). HIV stimulates innate immunity in two ways. It directly activates a subset of dendritic cells known as plasmacytoid dendritic cells, leading to production of large amounts of type I interferon, an antiviral cytokine that has been associated with disease progression [5,6]. HIV can also indirectly cause innate immune stimulation because the infection results in damage to the integrity of mucosal surfaces and the translocation of pro-inflammatory microbial products from the intestinal lumen into the circulation [7]. The ensuing release of inflammatory cytokines by innate immune cells may result in generalized immune cell activation, increasing $\mathrm{T}$ cell division and promoting senescence, apoptotic death or clearance by various mechanisms. Chronic immune activation may also result in bone marrow suppression, reduced thymic function and changes in lymphoid tissue architecture, all of which could reduce the capacity of the $\mathrm{T}$ cell pool to maintain itself.

The second possibility is the inverse - that HIV infection dysregulates $\mathrm{CD}_{4}^{+} \mathrm{T}$ cell homeostasis and that it is the decline in $\mathrm{CD}_{4}^{+} \mathrm{T}$ cell numbers that leads to chronic immune activation. However, HIV infection is associated with activation of multiple distinct branches of the immune system, and it is not obvious how this could reflect a simple homeostatic response to the loss of $\mathrm{CD} 4^{+} \mathrm{T}$ cells. It is also difficult to reconcile with the observation that there is a rapid decrease in levels of immune activation following antiretroviral therapy, despite persistent low $\mathrm{CD} 4^{+} \mathrm{T}$ cell numbers [8]. A variant of the $\mathrm{CD} 4^{+} \mathrm{T}$ depletion hypothesis more consistent with available data is that the loss of particular subsets of effector $\mathrm{CD} 4^{+} \mathrm{T}$ cells, presumably as a result of direct viral depletion, may contribute to generalized immune activation. For instance, the reduced level of $\mathrm{T}_{\mathrm{H}}$ 17-type $\mathrm{CD}^{+} \mathrm{T}$ cells (Figure 2) in the gastrointestinal tract has been proposed to have a key role in the loss of the integrity of the intestinal mucosa during HIV infection, enabling the translocation of microbial constituents from the intestinal tract into the systemic circulation, as discussed above [9]. It has also been suggested that a reduction in Tregs contributes to the aberrant levels of immune activation, as concluded by Marques et al. [1], although (as discussed in their paper and below) it is still unclear whether this population is indeed decreased during HIV infection [10].
Clearly, the two possible causal relationships between chronic immune activation and $\mathrm{CD} 4^{+} \mathrm{T}$ cell loss are not mutually exclusive. In fact, chronic immune activation and the loss of $\mathrm{CD}_{4}{ }^{+} \mathrm{T}$ cells may amplify each other in a loop that makes it difficult to establish which process underlies and drives the other.

Given the complexity of $\mathrm{T}$ cell dynamics and the numerous as yet undefined perturbations to normal $\mathrm{T}$ cell homeostasis that HIV is likely to induce either directly or indirectly, together with the difficulties in following the dynamic changes in the $\mathrm{T}$ cell compartment in the whole body in humans or primates, there is a case to be made for investigating aspects of HIV pathogenesis in mouse models. Although any results have to be extrapolated to the human system with caution, the extensive array of tools available in experimental mouse models to track the rates of division and death of $\mathrm{T}$ cells, the rates of flux between naïve and memory pools, and the maintenance of $\mathrm{T}$ cell populations over time within lymphoid and peripheral tissues enables a more complete accounting of $\mathrm{T}$ cell numbers to be undertaken.

Marques et al. [1] suggest that the OX40-DTA mouse is one approach to this issue and that the findings in these mice provide insight into the control of lymphocyte dynamics in HIV-infected humans. Indeed, in the absence of exogenous infection, OX40-DTA mice do show features consistent with generalized immune activation (Table 1), including an expansion of memory $\mathrm{CD}^{+} \mathrm{T}$ cell numbers that inverts the usual $\mathrm{CD}_{4}^{+}: \mathrm{CD}^{+} \mathrm{T}$ cell ratio, and increased serum levels of inflammatory cytokines. This generalized activation cannot be attributed to the release of

Table 1

Cellular dynamics in OX40-DTA mouse model [1]

\begin{tabular}{|c|c|c|c|c|}
\hline & & $\begin{array}{l}\text { Numbers (\%) } \\
\left(\mathrm{YFP}^{+}(\%)^{\dagger}\right)\end{array}$ & Turnover & Death $\ddagger$ \\
\hline \multirow[t]{3}{*}{$\mathrm{CD}^{+}$} & Naïve & $-12(8)$ & $\mathrm{CFSE} \uparrow, \mathrm{Ki} 67 \approx, \mathrm{BrdU} \approx$ & ND§ \\
\hline & Memory & $0(55)$ & $\mathrm{Ki} 67 \uparrow, \mathrm{BrdU} \approx$ & $\uparrow$ \\
\hline & Treg & $-40(80)$ & $\mathrm{Ki} 67 \uparrow, \mathrm{BrdU} \uparrow$ & $\uparrow$ \\
\hline \multirow[t]{2}{*}{$\mathrm{CD}^{+}$} & Naïve & $+4(1)$ & CFSE $\approx$ & ND \\
\hline & Memory & +133(3) & $\mathrm{BrdU} \approx$ & ND \\
\hline B cells & & +53 & & \\
\hline
\end{tabular}

*Percentage decrease or increase in cell population numbers compared with normal controls. †Percentage of cell population marked for DTAmediated deletion by the yellow fluorescent protein marker (YFP). ‡Determined by loss of BrdU-labeled cells, which might also be influenced by dilution of label following proliferation. ND, not done; $\approx$, approximately equal to normal controls; $\uparrow$, increased compared with normal controls; §BrdU labeling was too low to be determined. The method by which cell turnover was assessed is indicated: BrdU, bromodeoxyuridine, is incorporated into the DNA of proliferating cells upon administration to mice; CFSE, carboxyfluorescein succinimidyl ester, is diluted out from adoptively transferred CFSE-labeled cells with each successive division; Ki67, a protein that is expressed in the nucleus of recently divided cells. 
microbial components into the circulation from the gut, because deletion of activated $\mathrm{CD} 4^{+} \mathrm{T}$ cells does not in itself lead to a breach in the gut epithelium. Notably, Marques et al. [1] show that the expansion of effector $\mathrm{CD}^{+} \mathrm{T}$ cells and increases in serum levels of inflammatory cytokines can be reversed following reintroduction of Tregs from normal mice, suggesting that the increased immune activation in OX40-DTA mice can in part be ascribed to a Treg insufficiency, which they propose is a key event in HIV-infected individuals leading to $\mathrm{CD}_{4}{ }^{+} \mathrm{T}$ cell depletion. However, the reality is a bit more complicated, as we discuss below.

\section{T cell dynamics in OX40-DTA mice and HIV- infected humans}

Changes in the underlying dynamics of the $\mathrm{CD} 4^{+}$and $\mathrm{CD} 8^{+}$ $\mathrm{T}$ cell compartments in the OX40-DTA mouse are summarized in Table 1 and Figure 3. Although there is no alteration in the size of the naïve and memory $\mathrm{CD} 4^{+} \mathrm{T}$ cell pools, there is an increase in the rate of entry of naïve $\mathrm{CD}_{4}{ }^{+}$ $\mathrm{T}$ cells into the memory compartment, and an increase in turnover in both. In contrast, the rate of entry of naïve $\mathrm{CD}^{+} \mathrm{T}$ cells into the memory compartment remains unchanged, but the size of the memory $\mathrm{CD}^{+} \mathrm{T}$ cell compartment is almost doubled (Figure 3).

Naïve and memory $\mathrm{CD} 4^{+} \mathrm{T}$ cell division and death rates (turnover) are increased in both HIV infection and the OX40-DTA mouse. However, whether the increased turnover of the $\mathrm{CD}_{4}{ }^{+}$compartment in the OX40-DTA mouse is a result of Treg depletion or of the deletion of activated cells, or both, is not yet clear. If the increased recruitment of naïve $\mathrm{CD}_{4}{ }^{+} \mathrm{T}$ cells in OX40-DTA mice is due to Treg depletion, why are naïve $\mathrm{CD}^{+} \mathrm{T}$ cells unaffected by the loss of these regulatory cells? Perhaps the more likely explanation for the increased turnover of the naïve and memory $\mathrm{CD} 4^{+} \mathrm{T}$ cell pool is that it results directly from the continuous depletion of activated $\mathrm{CD}_{4}{ }^{+}$ $\mathrm{T}$ cells, which provides empty niches and removes the competition for signals (cytokines and other molecules) required for transit into the activated/memory pool. This would explain why naïve $\mathrm{CD} 4^{+} \mathrm{T}$ cells but not naïve $\mathrm{CD} 8^{+}$ $\mathrm{T}$ cells are being recruited to the memory pool in the OX40-DTA mouse.

It is still a matter of debate whether continuous recruitment of naïve $\mathrm{T}$ cells is required to maintain $\mathrm{CD} 4^{+} \mathrm{T}$ cell numbers during HIV infection, because memory cells themselves are self-renewing. On one hand, the increased naïve $\mathrm{T}$ cell turnover and decreased naïve $\mathrm{T}$ cell numbers during HIV infection $[8,11]$ have led to the hypothesis that progression to AIDS occurs because continuous recruitment of naïve $\mathrm{T}$ cells is required to maintain the memory pool and this eventually becomes unsustainable [12]. On the other hand, SIV-infected rhesus macaques can progress to AIDS without naïve $\mathrm{CD} 4^{+} \mathrm{T}$ cell depletion [13],

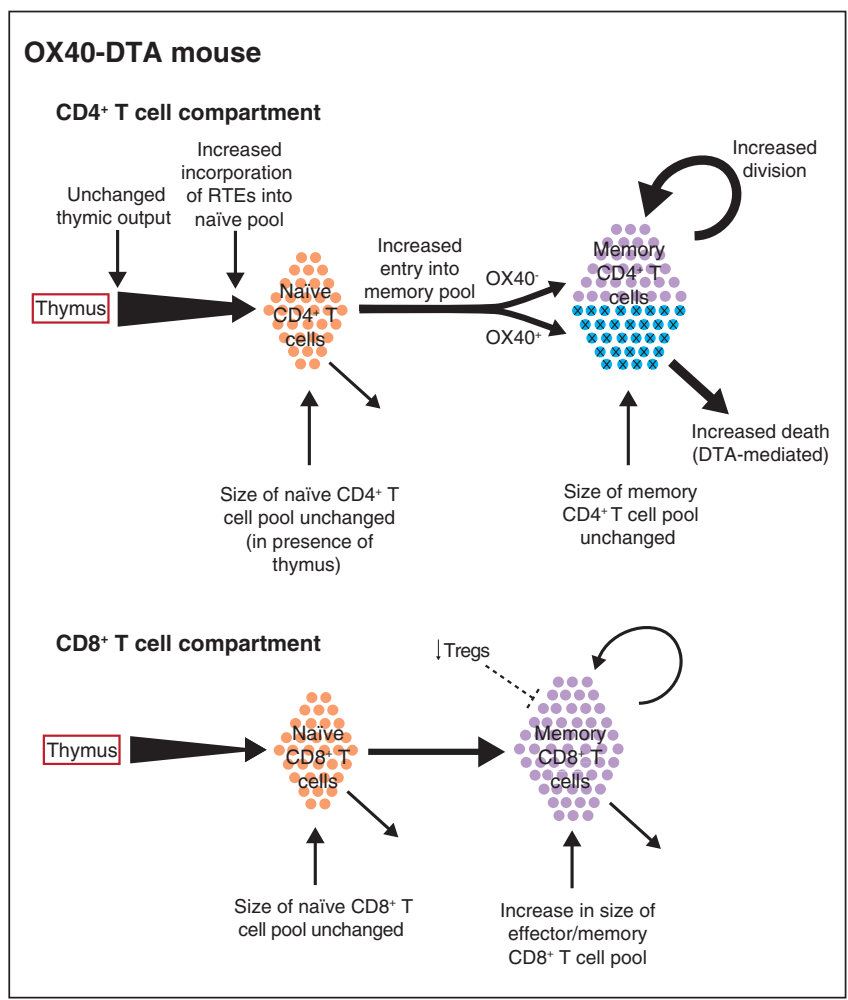

Figure 3

Schematic diagram of dynamic changes in T cell compartments described in OX40-DTA mice [1]. The changes in the widths of the arrows from Figure 1 denote the changes in rates of death and division or of transit from one pool to another compared to normal mice. RTEs, recent thymic emigrants.

arguing against a role for $\mathrm{CD}_{4}{ }^{+}$naïve $\mathrm{T}$ cell depletion in disease progression. However, in SIV-infected rhesus macaques, in which disease progression is generally faster than it is in HIV-infected humans, decreases in naïve $\mathrm{CD} 4^{+}$ $\mathrm{T}$ cell numbers have been observed over time in animals with slower disease progression, while $\mathrm{CD}_{4}^{+} \mathrm{T}$ cell numbers in more rapidly progressing animals remain near-normal [14]. This might imply that continuously recruiting naïve $\mathrm{T}$ cells into the memory pool can actually delay disease progression.

What do we learn from the OX40-DTA mouse? In these animals, even the ongoing depletion of nearly all activated $\mathrm{CD}_{4}{ }^{+} \mathrm{T}$ cells does not result in the progressive erosion of naïve and memory $\mathrm{CD} 4^{+} \mathrm{T}$ cells seen during HIV infection [1]. Thus, artificially increasing the death of activated $\mathrm{CD} 4^{+}$ $\mathrm{T}$ cells does not, on its own, seem to have any impact on $\mathrm{CD}_{4}{ }^{+} \mathrm{T}$ cell compartment homeostasis. However, this may, at least in part, reflect a difference between humans and mice, in that thymic output in adult mice is relatively high compared with that of humans in mid-life [15] and could counteract the losses in the naïve $\mathrm{CD}_{4}{ }^{+} \mathrm{T}$ cell pool in the OX40-DTA mouse. There are other important differences 
in lymphoid dynamics between the OX40-DTA mouse and HIV-infected humans: memory $\mathrm{CD}^{+} \mathrm{T}$ cell numbers are increased in both, yet although memory $\mathrm{CD}^{+}$turnover seems unaffected in OX40-DTA mice, it is increased during HIV infection [8]. Naïve CD8 ${ }^{+} \mathrm{T}$ cell numbers and recruitment are unaltered in the OX40-DTA mouse model, whereas naïve $\mathrm{CD}^{+} \mathrm{T}$ cell numbers are decreased and their proliferation is increased during HIV infection [8,11]. These considerations limit the extent to which data in the mouse can be directly extrapolated to HIV-infected humans.

\section{Regulatory T cells in HIV infection}

Is the role suggested by Marques et al. [1] for Tregs in immune activation in the OX40-DTA mouse consistent with what we know about HIV infection? This question is not straightforward to answer. HIV does not demonstrably infect Tregs at a higher frequency than non-Treg $\mathrm{CD} 4^{+}$ $\mathrm{T}$ cells [16], so these cells would not be expected to be deleted preferentially as is the case in the OX40-DTA mouse. But neither the role nor the status of Tregs in HIV infection is clear. First, opposing roles have been hypothesized for Tregs [10,17], each with some evidence to support it. On the one hand, Tregs are thought to have a detrimental effect during HIV infection by suppressing anti-HIV immune responses. Indeed, a positive correlation has been described between the fraction of Tregs within the $\mathrm{CD}_{4}{ }^{+} \mathrm{T}$ cell pool and viral load (reviewed in [10]). On the other hand, Tregs have been hypothesized to be beneficial by reducing chronic immune activation and limiting inflammatory responses. Evidence for this comes from studies showing a negative correlation between the percentage of Tregs within total $\mathrm{T}$ cells and both $\mathrm{CD} 4^{+}$and $\mathrm{CD}^{+} \mathrm{T}$ cell activation [17]. Second, the status of Tregs in HIV-infected individuals is murky, with reports suggesting both increased and decreased numbers, perhaps because of different assays used to measure the size of this compartment. Furthermore, in correlating disease progression with Tregs, the measure of Tregs that is used (for example, the Treg fraction within $\mathrm{CD} 4^{+} \mathrm{T}$ cells, within total $\mathrm{T}$ cells or within total hematopoietic cells, or the absolute numbers of Tregs) can greatly influence the outcome of the analysis. Part of the problem is that whereas in mice Tregs can be unambiguously identified by two markers - the transcription factor FoxP3, which is exclusively expressed by Tregs in this species, and high levels of CD25, a cytokine receptor expressed on activated $\mathrm{T}$ cells - in humans, CD25 levels on Tregs are only marginally higher than those on effector $\mathrm{CD} 4^{+} \mathrm{T}$ cells, and FoxP3 is not exclusively expressed by Tregs, so they are more difficult to quantify accurately.

\section{The role of microbial translocation}

During HIV infection, high systemic levels of the microbial product lipopolysaccharide, a potent inflammatory stimulus also known as endotoxin, have been shown to correlate with increased T cell activation. Despite this correlation, it has not been clear whether endotoxemia directly causes chronic immune activation and concomitant $\mathrm{CD} 4^{+} \mathrm{T}$ cell depletion, or whether it only reflects loss of $\mathrm{CD} 4^{+}$host protection or the amount of mucosal damage by existing levels of immune activation. Marques et al. [1] have addressed this important question by extending their studies to a second model mouse (the NEMO mouse [18]), which is engineered to allow systemic leakage of microbial components from the gut (known as microbial translocation), and they do not detect any striking effects on $\mathrm{T}$ cell numbers or incorporation of bromodeoxyuridine (BrdU) in these mice, suggesting that microbial translocation may not be the cause of general immune activation. However, further analysis is warranted before a role for microbial translocation on $\mathrm{T}$ cell dynamics can be excluded.

\section{A reductionist approach to HIV pathogenesis}

Where do all these twists and turns leave us, especially with respect to the insights that can be gleaned from the Marques et al. study [1]? Although mouse models are unlikely to entirely reproduce the complex etiology of AIDS, there is a clear need to shed more light on the dynamic processes underlying disease progression during HIV infection, and experimental models may provide important opportunities to do so. With the goal of investigating key processes in the absence of direct infection, rather than replicating HIV pathogenesis, it is likely that not only the similarities with HIV infection, but also the differences, will teach us something about the basic biology of the system. For instance, the study by Marques et al. [1] highlights the impact that the depletion of activated $\mathrm{CD} 4^{+} \mathrm{T}$ cells can have on the dynamics of the $\mathrm{CD}^{+} \mathrm{T}$ cell pool and shows that imbalances that result from this process can, by causing a deficiency of Tregs, affect other branches of the immune system. Interestingly, in this mouse model the depletion of activated $\mathrm{CD} 4^{+} \mathrm{T}$ cells does not progressively erode the $\mathrm{CD} 4^{+} \mathrm{T}$ cell pool, suggesting that even removing a large proportion of activated $\mathrm{CD}_{4}{ }^{+} \mathrm{T}$ cells does not, on its own, impair the renewal capacity of the $\mathrm{CD} 4^{+} \mathrm{T}$ cell compartment. (However, the continuous recruitment of naïve $\mathrm{CD} 4^{+} \mathrm{T}$ cells was required to prevent the erosion of the $\mathrm{CD} 4^{+} \mathrm{T}$ cell pool, and as we pointed out earlier, this may be harder to sustain in humans because of loss of thymic function). In addition, systemic microbial translocation did not induce any immediate changes resembling the cellular dynamics seen during HIV infection.

Overall, insights gained from such reductionist approaches might inform studies more difficult to undertake in humans or primates. In addition, they may generate novel hypotheses as to how the balance of production and loss of $\mathrm{CD} 4^{+} \mathrm{T}$ cells can be therapeutically altered in the setting of HIV infection to prevent the decline of $\mathrm{CD}_{4}{ }^{+} \mathrm{T}$ cells or restore their renewal capacity. 


\section{Acknowledgements}

The authors' work is supported by the Intramural Research Program of NIAID, NIH, by The Netherlands Organization for Scientific Research (NV) and by the NIH Office of AIDS Research (JNM). The opinions expressed in this article are those of the authors and do not necessarily reflect official views of NIAID or NIH.

\section{References}

1. Marques R, Williams A, Eksmond U, Wullaert A, Killeen N, Pasparakis M, Kioussis D, Kassiotis G: Generalized immune activation as a direct result of activated CD4 T cell killing. $J$ Biol 2009, 8:93.

2. Croft M, So T, Duan W, Soroosh P: The significance of OX40 and OX40L to T-cell biology and immune disease. Immunol Rev 2009, 229:173-191.

3. Takeda I, Ine S, Killeen N, Ndhlovu LC, Murata K, Satomi S, Sugamura K, Ishii N: Distinct roles for the OX40-0X40 ligand interaction in regulatory and nonregulatory T cells. $J$ Immunol 2004, 172:3580-3589.

4. Silvestri G, Sodora DL, Koup RA, Paiardini M, O'Neil SP, McClure HM, Staprans SI, Feinberg MB: Nonpathogenic SIV infection of sooty mangabeys is characterized by limited bystander immunopathology despite chronic high-level viremia. Immunity 2003, 18:441-452.

5. Mandl JN, Barry AP, Vanderford TH, Kozyr N, Chavan R, Klucking S, Barrat FJ, Coffman RL, Staprans S, Feinberg MB: Divergent TLR7/9 signaling and type I interferon production distinguish pathogenic and non-pathogenic SIV infections. Nat Med 2008, 14:1077-1087.

6. Meier A, Chang JJ, Chan ES, Pollard RB, Sidhu HK, Kulkarni S, Wen TF, Lindsay RJ, Orellana L, Mildvan D, Bazner S, Streeck H, Alter G, Lifson JD, Carrington M, Bosch RJ, Robbins GK, Altfeld M: Sex differences in the Toll-like receptor-mediated response of plasmacytoid dendritic cells to HIV-1. Nature Med 2009, 15:955-959.

7. Brenchley JM, Price DA, Schacker TW, Asher TE, Silvestri G, Rao S, Kazzaz Z, Bornstein E, Lambotte O, Altmann D, Blazar BR, Rodriguez B, Teixeira-Johnson L, Landay A, Martin JN, Hecht FM, Picker LJ, Lederman MM, Deeks SG, Douek DC: Microbial translocation is a cause of systemic immune activation in chronic HIV infection. Nat Med 2006, 12:13651371.

8. Hazenberg MD, Stuart JW, Otto SA, Borleffs JC, Boucher CA, de Boer RJ, Miedema F, Hamann D: T-cell division in human immunodeficiency virus (HIV)-1 infection is mainly due to immune activation: a longitudinal analysis in patients before and during highly active antiretroviral therapy (HAART). Blood 2000, 95:249-255.

9. Brenchley JM, Paiardini M, Knox KS, Asher Al, Cervasi B, Asher TE, Scheinberg P, Price DA, Hage CA, Kholi LM, Khoruts A, Frank I, Else J, Schacker T, Silvestri G, Douek DC:
Differential Th17 CD4 T cell depletion in pathogenic and nonpathogenic lentiviral infections. Blood 2008, 112:28262835.

10. de St Groth BF, Landay AL: Regulatory T cells in HIV infection: pathogenic or protective participants in the immune response? AIDS 2008, 22:671-683.

11. Roederer M, Dubs JG, Anderson MT, Raju PA, Herzenberg LA: CD8 naive T cell counts decrease progressively in HIVinfected adults. J Clin Invest 1995, 95:2061-2066.

12. Hazenberg MD, Hamann D, Schuitemaker H, Miedema F: T cell depletion in HIV-1 infection: how CD4+ T cells go out of stock. Nat Immunol 2000, 1:285-289.

13. Okoye A, Meier-Schellersheim M, Brenchley JM, Hagen SI, Walker JM, Rohankhedkar M, Lum R, Edgar JB, Planer SL, Legasse A, Sylwester AW, Piatak M Jr, Lifson JD, Maino VC, Sodora DL, Douek DC, Axthelm MK, Grossman Z, Picker LJ: Progressive CD4+ central memory $T$ cell decline results in CD4+ effector memory insufficiency and overt disease in chronic SIV infection. J Exp Med 2007, 204:2171-2185.

14. Brown CR, Czapiga M, Kabat J, Dang Q, Ourmanov I, Nishimura $Y$, Martin MA, Hirsch VM: Unique pathology in simian immunodeficiency virus-infected rapid progressor macaques is consistent with a pathogenesis distinct from that of classical AIDS. J Virol 2007, 81:5594-5606.

15. Vrisekoop N, den Braber I, de Boer AB, Ruiter AF, Ackermans MT, van der Crabben SN, Schrijver EH, Spierenburg G Sauerwein HP, Hazenberg MD, de Boer RJ, Miedema F, Borghans JA, Tesselaar K: Sparse production but preferential incorporation of recently produced naive T cells in the human peripheral pool. Proc Natl Acad Sci USA 2008 105:6115-6120

16. Chase AJ, Yang HC, Zhang H, Blankson JN, Siliciano RF: Preservation of FoxP3+ regulatory $\mathrm{T}$ cells in the peripheral blood of human immunodeficiency virus type 1-infected elite suppressors correlates with low CD4+ T-cell activation. J Virol 2008, 82:8307-8315.

17. Eggena MP, Barugahare $B$, Jones $N$, Okello M, Mutalya $S$, Kityo C, Mugyenyi P, Cao H: Depletion of regulatory T cells in HIV infection is associated with immune activation. $J$ Immunol 2005, 174:4407-4414.

18. Nenci A, Becker C, Wullaert A, Gareus R, van Loo G, Danese $S$, Huth M, Nikolaev A, Neufert C, Madison B, Gumucio D, Neurath MF, Pasparakis M: Epithelial NEMO links innate immunity to chronic intestinal inflammation. Nature 2007 446:557-561.

Published: 27 November 2009

doi:10.1186/jbiol198

(c) 2009 BioMed Central Ltd 